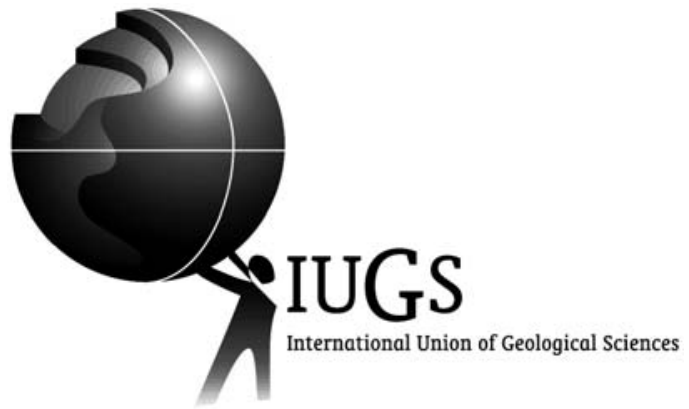

\section{From the Chair}

Disseminating scientific knowledge has always been a key topic in IUGS' activities. The Union has produced a range of publications (books, journals, maps, charts), both on its own and in cooperation with other organizations and publishers. Some of these works have been concerned with geological standards, while others have been overviews of current topics, conference proceedings, and books on regional geology. In 1980, IUGS began its own numbered series of monographs: number 36 was the last in this series. These ranged from slim reports on stratigraphic correlation, which were printed and distributed by the Union, to books on remote sensing, metallogenesis of Latin America, and the Carboniferous of Asia, which were printed and distributed by others on behalf of IUGS. Over the past five years approximately 70 monographs or books were published on the work of the IUGS Commissions and IGCP. Some 30 were issued and sold by major publishing houses, and the rest were produced by universities, museums, scientific societies, and government agencies, such as geological surveys.

IUGS faces increasing difficulties in handling its publications. In the past an Advisory Board of Publications had to deal with all such publications and safeguard quality and procedures before publishing. It became also involved in marketing, sales, legal, warehousing and technical issues. In February 2001 the IUGS Executive Committee (EC) concluded that it had neither the resources nor the expertise to continue to do this. Moreover, the Union intends to raise the profile and dissemination of its scientific work and should therefore not spend its time on non-scientific aspects of publication. The EC agreed with a new publication policy proposed this year by its new Publications Committee. This policy is based on the notion that publications remain important to the Union but that the non-scientific work involved should primarily be out-

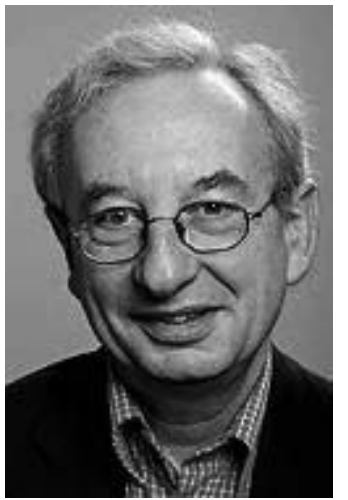

sourced to a professional publishing house. In March 2003 this house was found and on 8 April I signed a contract with the Geological Society of London (GSL), which has an excellent record in publishing high-quality geoscience books. Under this arrangement GSL will publish selected manuscripts submitted by IUGS Commissions, Committees, Task Groups, Initiatives and IGCP Projects. Works approved for publication will go through normal GSL procedures and will clearly acknowledge IUGS and display the Union's logo. Reduced sales prices may apply, and royalties from the books sold may be returned to the Union. With this arrangement two important targets have been achieved: firstly, the professional level of non-serial IUGS publications will greatly increase while giving proper recognition to the Union's work. Secondly, the Union has discharged a massive and increasing work load not belonging to its core business. The first book to be published through this arrangement will be the 2002 Brunel Conference on 'Environmental Catastrophes and Recovery in the Holocene', edited by Suzanne Leroy and Iain Stewart.

Eduardo F. J. de Mulder

President, International Union of Geological Sciences 